\title{
Marketing Oriented and Sales Oriented Companies in the Agro-Food Industry
}

\author{
Gabriela CHICIUDEAN*, Felix ARION and Iulia MUREȘAN
}

University of Agricultural Sciences and Veterinary Medicine Cluj-Napoca, Faculty of Horticulture, Calea Mănăștur 3-5, 400372, Cluj-Napoca, Cluj, Romania

*)Corresponding author, e-mail: gabriela_chirla@yahoo.com

BulletinUASVM Horticulture 72(2) / 2015

Print ISSN 1843-5254, Electronic ISSN 1843-5394

DOI:10.15835/buasvmcn-hort:11491

\begin{abstract}
A strong marketing orientation within organizations is considered able to create a competitive edge and having a positive impact on the company's performance. Its' necessity is obvious especially in the last decades when companies face mature markets and the key for surviving consists in approaching a marketing - oriented strategy, by keeping a strong relationship with all the stakeholders. Marketing-oriented companies are more likely to survive than the sales-oriented ones. The principal aim of this research was to investigate whether the agro-food companies from Cluj County have a marketing - oriented activity, given its' importance within the agro-food sector. A survey has been conducted among the agro-food companies from Cluj County in 2012 using the questionnaire which comprised a section with seven affirmations regarding marketing orientation. Data interpretation was based on statistical methods such as: Factor Analysis and Cluster Analysis. Results indicated that the agro-food companies from Cluj County are more sales - oriented than marketing-oriented, which means that all they focus mainly on increasing the sales volume. More than half of the total sample of companies interviewed is more interested in promotion and market studies than building a strong relationship with stakeholders. Only 19 companies are marketing - oriented, being interested in designing products according to market demand and customer preference, but also about their employees and their personal satisfaction. In conclusion, the agro-food companies from Cluj-County are more sales - oriented than marketing - oriented when facing the market, which on medium and long term could have negative impact on companies' performance.
\end{abstract}

Keywords: Cluj County, customer satisfaction, marketing audit.

\section{INTRODUCTION}

The concept of marketing orientation is a relatively recent one. Starting with the 50's companies became more interested in gaining customer fidelity and marketing theory started to link the degree of marketing orientation with the company's performance (Guenzi and Trolio, 2006; Hingley and Lindgreen, 2010).

A strong and efficient marketing orientation implies that companies focus their efforts towards assuring a high customer satisfaction which throughout their fidelity will contribute indirectly to their sustainability and a high profit (Crawford, 2006). The author sustains the idea and the necessity of a strong marketing orientation especially within the agro-food sector because of its proximity to the consumer.

Baker (1989) considers that the producers need to begin their activity after identifying and specifying the customers targeted and after that to mobilize all the companies' assets in order to satisfy their needs and desires. Sin et al. (2005) highlights the relationship between adopting a marketing orientation and having a competitive advantage which will certainly have a positive impact over the company's performance. A strong marketing orientation is considered to have both financial and non-financial advantages for the firm (Lingsa and Greenleyb, 2009). The fact that marketing-oriented companies perform better 
than the sales-oriented companies is underlined also by Dauda and Akingbade (2010). The necessity of a marketing orientation becomes more and more obvious because of the rapid changes occurred during the last decades which affected both markets and consumers. The markets are nowadays characterized by an intense dynamicity and a strong competitiveness, while the consumers have easy access to information and many possibilities to satisfy their needs and desires (Bhardwaj, 2007). Alrubaiee and Al-Nazer (2010) consider that all these shifts occurred within the marketing environment can be controlled by the company only by adopting a marketing-oriented strategy, a key for obtaining customer loyalty. Avlonitis and Gounaris (1997) identified three main factors which could indicate a marketing orientation within the company: actions meant to cope with market changes (market analysis, research marketing); promotion, obtaining wellpositioned products, customers' satisfaction (cultural approach); actions for keeping a contact with the marketplace (promotion, sales). The research conducted among Greek companies divided them into three categories: marketingoriented companies, product-oriented companies and sales-oriented companies (Avlonitis and Gounaris, 1999). The importance of this research consists in the possibility to categorize the companies according to their position towards market, indicating their ability to conduct a sustainable and performant business. The existence of a link between marketing orientation and business performance was tested among companies from different countries. So, Mahmoud (2011) conducted a study among the managers of SMEs from Accra and Tema (Ghana) and the results indicated a strong connection between the two concepts. Taghian and Shaw (2008) conducted a study among Australian companies and results indicate the same link between marketing orientation and business performance.

The principal aim of this research was to investigate whether the agro-food companies from Cluj County have a marketing - oriented activity, given its' importance in obtaining a long term performance, within an economic sector which is directly relate to the consumer primary needs of food.

The objectives of this study are: to investigate the type of orientation among the agro-food companies (marketing orientation or sales orientation); to identify the main characteristics of the agro-food companies (sales-oriented and marketing-oriented) from Cluj County in terms of: domain of activity, number of employees and turnover.

\section{MATERIAL AND METHODS}

In order to achieve the goal of the research, a study has been conducted in 2012 in Cluj County among the agro-food companies. The instrument used was the questionnaire which had three main sections: the first section was dedicated to all companies whether they conducted or not a marketing audit; the second section was addressed to companies that did not conduct a marketing audit and finally the third part was addressed only to those companies which conducted one. The first section comprises a question with seven statements regarding company's attitudes towards market approach and the consumer, using a sevenpoint Likert scale. Based on those statements, companies could be segmented in sales-oriented and marketing-oriented.

The survey comprised three stages: developing the questionnaire and pre-testing, followed by a face to face questionnaire administration among marketers and managers within the agro-food companies. In Cluj County in 2012 there were 571 agro-food companies according to data from the Trade Registry Commerce. The representative sample was calculated taking into consideration the company's age on the market. Taghian and Shaw (2008) concluded in his research among the Australian companies that conducting a marketing audit is strongly related to the company's age on the market, meaning older companies are more likely to conduct a marketing audit than the new ones. The mean age on the market is 13.6 years. The sample volumes consisted in 46 agro-food companies, but for a better result validation 51 questionnaire were included.

The absolute value of the error was determined using the formula (Merce et al., 2010):

$$
\Delta_{\widetilde{\mathrm{x}}}=\frac{\mathrm{R}_{\widetilde{\mathrm{x}}} \bullet \mathrm{X}_{\max }}{100}=\frac{8 \bullet 22}{100}=1,76
$$

Where $\Delta_{\widetilde{\mathrm{x}}}$ - absolute value of the error limit $\mathrm{R}_{\widetilde{\mathrm{x}}}$ - the relative value of the error limit 
$\mathrm{X}_{\max }$ - the maximum value of the characteristic "company's age on the market".

Sample volume (n) was determined taking into account the characteristic "medium age on the market" which is 13.6 years:

$$
\sigma_{\mathrm{x}}^{2}=\frac{\sum_{j=1}^{k}\left(x_{j}-\bar{x}\right)^{2} N_{j}}{\sum_{j=1}^{k} N_{j}}=40.32
$$

Where $\sigma_{\mathrm{x}}^{2}$ - dispersion

$\mathrm{X}$ - the mean value for the characteristic "age on the market"

Sample volume was determined using the following formula (Merce et al., 2010):

$\frac{k^{2} * \sigma_{x}^{2}}{J_{x}^{2}+\frac{k^{2} * \sigma_{x}^{2}}{N}}=\frac{(1.96)^{2} * 40.32}{(1,76)^{2}+\frac{(1.96)^{2} * 40.32}{571}}=45.98$ companies $\cong 46$ companies

In order to determine the importance of different aspects regarding marketing orientation marketers/managers were asked to express their agreement using a seven-point scale were 1 means totally unimportant and 7- very important. The statements were extracted from Kotler et al. (2005) and tested in similar studies conducted in countries like Australia (Taghian and Shaw, 2008) Greece (Avlonities and Gounaries, 1999), Nigeria (Dauda and Akingbade, 2010) or Ghana (Mahmoud, 2011).

The main aim of the research is to investigate if the agro-food companies from Cluj County have a marketing orientation. The statistical methods used were: Factor Analysis, Keiser Meyer Olkin
Test, Bartlett's Test of Sphericity, K-Means Cluster Analysis and Discriminant Analysis. The Factor Analysis based on the Principal Component Analysis has the main role to reduce the variables to significant ones. The Keiser Meyer Olkin Test was used to measure the sample adequacy, while for testing the items' correlation; Bartlett's Test of Sphericity was used. The K-means Cluster analysis offered the possibility to group the companies based on the factors obtained. Discriminant Analysis was used to determining the characteristics of each group.

\section{RESULTS AND DISCUSSIONS}

From the seven statements referring to marketing orientation it can be observed (Tab. 1) that the agro-food companies from Cluj County consider very important obtaining the customer satisfaction regarding their products $($ mean $=6.55)$ with a standard deviation of 0.673 . The results are significantly different from the one obtained in Nigeria by Dauda and Akingbade (2010), were the mean for customer satisfaction was 4.56 indicating a medium interest for the issue less strong than in the case of Romanian companies. Almost as important as the first statement is considered to be the statement referring to obtaining products according to customers' needs (mean $=6.22$ ) with a standard deviation of 1.064. The results are encouraging from the point of view of marketing, because they indicate that managers or marketers from the agro-food companies are aware of the importance of being connected to the market and the consumers, but after analyzing the other statements like "adopting marketing mix strategies" (mean $=4.61$ ), "allocating funds for promotion" (4.24) or "conducting/buying marketing studies" (mean $=3.57$ ) it can be

Tab. 1 Mean values for each of the statements regarding the marketing orientation

\begin{tabular}{cccc}
\hline No. & Statements & Mean & Std. Deviation \\
\hline 1. & Customer satisfaction regarding the products & 6.55 & 0.673 \\
\hline 2. & Obtaining products according to customers' needs & 6.22 & 1.064 \\
\hline 3. & Actions for gaining customers loyalty & 4.71 & 2.138 \\
\hline 4. & Employers' satisfaction & 5.18 & 2.037 \\
\hline 5. & Adopting marketing-mix strategies & 4.61 & 1.919 \\
\hline 6. & Allocating funds for promotion & 4.24 & 2.103 \\
\hline 7. & Conducting/Buying marketing studies & 3.57 & 2.032 \\
\hline
\end{tabular}


concluded that they do not find important concrete actions for keeping in touch with the market.

The first statement referred to "customer satisfaction regarding products offered". For $64.71 \%$ this aspect is very important, while only for $9.80 \%$ it is partially important (Tab. 2).

“Obtaining products according to consumers' demands" is an important aspect only for $54.90 \%$ of the respondents while $1.94 \%$ is unimportant, issue which reflects the reality among the Romanian agro-food companies of producing what they can, not what they should after a market research."The actions for gaining customer loyalty" is an important aspect for $29.41 \%$ of the companies and a totally unimportant one for $11.76 \%$. The high percentages of companies that do not consider loyalty being important probably have a decision-making factor for which loyalty is simply a useless cost, not having immediate effects. Statement refers at the importance of adopting marketing - mix strategies which are very important only for $19.61 \%$ of the respondents, fact that could be explained by a general lack of business strategic planning among the agro-food companies. This situation leads on a medium and long term to incapacity of coping with the marketing environment. For only 41.20 $\%$ of the respondents the employers' satisfaction is very important while for a high percentage of $9.80 \%$ is totally unimportant issue. The agro-food industry should pay much more attention to their employees because unsatisfied employees behave like unsatisfied customers and their negative worth to mouth publicity can have a stronger impact on the market.
In order to identify the type of orientation existing among the agro-food companies, Factor Analysis was used based on the Principal Component Analysis. Seven factors were generated but only the first two met the criteria (eigenvalue $>=1$ ), factor solution explaining $71.898 \%$ of the total variance. The first factor was named "marketing orientation" because of its' content focused on the consumer which is the central element. The factor indicates preoccupation for gaining customer loyalty, products according to customer's needs, actions for gaining customers' loyalty and satisfied employees at their working place. The second factor was named "sales oriented" because it indicates a strong preoccupation for increasing their sales being focused on market studies, promotion and marketing mix strategies (Tab. 3).

K-means Cluster analysis and Discriminant Analysis indicated two groups negatively related one to another, so the first group is interested of the first factor (marketing-oriented) while the second is interested of the second one (salesoriented). The first group comprises 19 agro-food companies and is marketing-oriented. The second group comprises 32 agro-food companies and is sales-oriented. The results are predictable and reflect the reality in almost every field of activity where companies are more interested in obtaining a rapid profit, instead of building a long term business.

The respondents activate in different fields of the agro-food industry from Cluj County. From this point of view, the study is different from the one performed by Mahmoud (2011) in Ghana, where the company's field of activity varied and service companies dominated the sample, or by

Tab. 2 Statements regarding marketing orientation and the percentage of responses for each one where 1- "totally unimportant" and 7 - "very important"

\begin{tabular}{cccccccc}
\hline Statements & $1(\%)$ & $2(\%)$ & $3(\%)$ & $4(\%)$ & $5(\%)$ & $6(\%)$ & $7(\%)$ \\
\hline $\begin{array}{c}\text { Customer satisfaction regarding the } \\
\text { products }\end{array}$ & 0 & 0 & 0 & 0 & 9.80 & 25.50 & 64.70 \\
\hline $\begin{array}{c}\text { Obtaining products according to } \\
\text { customers' needs }\end{array}$ & 0 & 2.00 & 0 & 2.00 & 21.60 & 19.60 & 54.90 \\
\hline Actions for gaining customers loyalty & 11.80 & 13.70 & 0 & 13.70 & 17.60 & 13.70 & 29.40 \\
\hline Employers' satisfaction & 5.90 & 9.80 & 7.80 & 13.70 & 3.90 & 17.60 & 41.20 \\
\hline Adopting marketing-mix strategies & 7.80 & 2.00 & 31.40 & 3.90 & 9.80 & 25.50 & 19.60 \\
\hline Allocating funds for promotion & 21.60 & 2.00 & 11.80 & 11.80 & 11.80 & 31.40 & 9.80 \\
\hline Conducting/Buying marketing studies & 27.50 & 7.80 & 9.80 & 21.60 & 5.90 & 23.50 & 3.90 \\
\hline
\end{tabular}


the one of Avlonities and Gounaries (1997) where industrial companies were analyzed together with goods companies. In Cluj, of the total sample of 51 companies, $31.37 \%$ are represented by bakeries, pastries and sugar products. The dairy industry is represented in the sample with a percentage of $19.61 \%$, while the meat industry holds a share of $17.65 \%$. Other fields of activity are: milling $(13.73 \%)$, fruits and vegetables preservation (5.88\%), alcoholic and non-alcoholic drinks (5.88\%), fish products producers $(3.92 \%)$ and oil producers (1.96\%).The marketing-oriented profile is encountered among companies which process meat and meat products (31.58\%), but also among those who process fruit and vegetables (10.53), while sales-oriented profile belongs to milk and dairy companies (21.88\%) (Tab. 4).

The number of employees working inside the companies analyzed is another indicator of their size and position on the market. The highest share belongs to medium-size companies with 10-49 employees, followed by companies with 50-249

Tab. 3 Factors obtained using Factor Analysis

\begin{tabular}{cc}
\hline Factors & Loadings \\
\hline Factor1 Marketing-oriented & \\
\hline Client satisfaction regarding the commercialized products & 0.880 \\
\hline Obtaining products according to consumers demands & 0.495 \\
\hline Actions for gaining client fidelity & 0.829 \\
\hline Satisfied employees at work & 0.842 \\
\hline Factor 2 Sales-oriented & 0.919 \\
\hline Adopting marketing mix strategies & 0.729 \\
\hline Allocation of funds for promotion & 0.870 \\
\hline Developing/ purchasing market studies & \\
\hline
\end{tabular}

Tab. 4 Companies profile according to their orientation

\begin{tabular}{|c|c|c|c|c|}
\hline & \multirow[b]{2}{*}{ Characteristic } & \multicolumn{2}{|c|}{ Company orientation } & \multirow[b]{2}{*}{$\begin{array}{c}\text { Percent of tota } \\
\text { (\%) }\end{array}$} \\
\hline & & $\begin{array}{c}\text { Marketing-oriented } \\
(37.25 \%)\end{array}$ & $\begin{array}{c}\text { Sales-oriented } \\
(62.75 \%)\end{array}$ & \\
\hline \multirow{8}{*}{$\begin{array}{l}\text { Field of activity } \\
\text { within the agro- } \\
\text { food sector }\end{array}$} & Meat and meat products & 31.58 & 9.38 & 17.65 \\
\hline & Fish and fish products & 0.00 & 6.25 & 3.92 \\
\hline & Fruits and vegetables preservation & 10.53 & 3.13 & 5.88 \\
\hline & Animal and vegetal oils and fats & 5.26 & 0.00 & 1.96 \\
\hline & Milk and dairy & 15.79 & 21.88 & 19.61 \\
\hline & Milling & 10.53 & 15.63 & 13.73 \\
\hline & Other food products & 26.32 & 34.38 & 31.37 \\
\hline & Alcoholic and non-alcoholic drinks & 0.00 & 9.38 & 5.88 \\
\hline \multirow{4}{*}{$\begin{array}{l}\text { Number of } \\
\text { employees }\end{array}$} & $1-9$ & 52.63 & 12.50 & 27.45 \\
\hline & $10-49$ & 26.32 & 40.63 & 35.29 \\
\hline & $50-249$ & 21.05 & 34.38 & 29.41 \\
\hline & $250-500$ & 0.00 & 16.67 & 7.84 \\
\hline \multirow{4}{*}{$\begin{array}{l}\text { Turnover } \\
\text { (Euro) }\end{array}$} & $0-35000$ & 21.05 & 6.25 & 11.76 \\
\hline & $35001-100000$ & 42.11 & 21.88 & 29.41 \\
\hline & $100001-2000000$ & 26.32 & 43.75 & 37.25 \\
\hline & $>2000000$ & 10.53 & 28.13 & 21.57 \\
\hline
\end{tabular}


employees (29.41\%). A high share has also small enterprises with 1-9 employees (27.45\%). At the opposite side are large companies with 250 500 employees with hold a share of only $7.85 \%$ in the total sample. It can be concluded that big companies with more than 250 employees hold a low percentage among the sample, while the SMEs are very well represented. Another observation is related to the high percentage of small industries which indicates whether a young business or a manufacture one. In terms of number of employees, an interesting fact can be observed: companies with fewer employees (1-9 and 10-49) are more marketing-oriented than the companies with a higher number of employees (more than 50). The results of the research conducted in Nigeria by Dauda and Akingbade (2010) indicate that small companies companies with a marketing-oriented approach recorded increasing performance and profitability.

The variable "turnover" in 2011 revealed a high share of companies with a turnover of 2,000,000 Euro and more (21.57\%), while $37.25 \%$ of the companies had a turnover of 100,001-2,000,000 Euro and $29.41 \%$ of the companies registered a turnover of 35,001-100,000 Euro. The smallest share belongs to companies with a turnover of $0-35,000$ Euro $(11.76 \%)$ fact explainable by the existence of new entries within the sample. The situation is similar in terms of turnover; smaller companies are more marketing-oriented than the larger ones according to results obtained (Tab. 4).

\section{CONCULSIONS}

The present study represents a starting point for a future and more complex research conducted in the North-Western region of Romania regarding marketing orientation and company's performance. In Romania a similar research does not exist.

Given the importance of the marketing orientation for the companies in terms of performance and sustainability, it can be concluded that the agro-food sector from Cluj County is characterized mainly by sales-oriented companies than of the marketing-oriented companies, which on long term could affect the business environment. Companies should focus more on the consumer and adapt their products according to his needs instead of following increasing market share by obtaining high volume of sales. The profile of the two groups of companies (marketing-oriented and sales-oriented) indicates that the number of small companies which are marketing-oriented is higher than the smaller companies which are sales-oriented. The fact could be explained by the company's age on the market. Larger companies with high level of turnover and a high number of employees have been activating on the agro-food market for a longer period and their main purpose is increasing the sales volume. Smaller companies do not have a long market experience, they are new on the market and try to compete using the concepts of marketing orientation, meaning placing the consumer in centre of their activity, assuring employers' satisfaction, obtaining customer's fidelity.

The main limitation of the study refers to the fact that the company's' performance was not analysed, mainly because of the managers' attitude which are not willing to offer data for such a research. Another limitation is related to the research area. For a complete investigation, agrofood companies from the main Romanian regions should be analysed. The study could be improved mostly by testing the same aspects among the consumer companies from the same area.

\section{REFERENCES}

1. Alrubaiee L, Al-Nazer N (2010). Investigate the Impact of Relationship Marketing Orientation on Customer Loyalty: The Customer's Perspective. International Journal of Marketing Studies 2(1):155-174.

2. Avlonitis G, Gounaris S (1997). Marketing Orientation and Company Performance: A Comparative Study of Industrial vs. Consumer Goods Companies, Industrial Marketing Management 26(5):1-18.

3. Avlonitis G, Gounaris S (1999). Marketing orientation and its determinants: An empirical analysis, European Journal of Marketing 33(11-12):1003-1037.

4. Baker M (1989). A new Philosophy of management? The quarterly review of marketing winter 1-4.

5. Bhardwaj D (2007). Relationship Marketing in Context to the IT Industry. VISION-TheJournal of Business Perspective 11(2): 57- 66.

6. Crawford IM (2006) Agricultural and food marketing management, FAO Agriculture dept.

7. Dauda YA, Akingbade WA (2010). Employee's Market Orientation and Business Performance in Nigeria: Analysis of Small Business Enterprises in Lagos State. International Journal of Marketing Studies, 2(2): 134-143.

8. Guenzi P, Troilo G (2006). Developing marketing capabilities for customer value creation through Marketing-Sales integration. Industrial Marketing Management 35:974-988. 
9. Hingley MK., Lindgreen A (2010). Market Orientation: Transforming Food and Agribusiness around the Customer Gower Publishing, England, p. 3

10. Kotler P, Gregor WT, Rogers WIII (2005). Marketing audit comes of age, Sloan Management Review. Classic reprint, 1-30.

11. Lingsa IN, Greenleyb GE (2009). The impact of internal and external market orientations on firm performance. Journal of Strategic Marketing, 17(1):41-53.

12. Mahmoud MA (2011). Market Orientation and Business Performance among SMEs in Ghana. International Business Research 4(1)2:41-251.
13. Merce E, Merce CC, Dumitraş D (2010). Prelucrarea statistică a datelor, AcademicPres, Cluj-Napoca.

14. Sin LYM, TseACB, Yau OHM, Chow RPM, Lee JSY, Lau LBY (2005). Relationship marketing orientation: scale development and cross-cultural validation. Journal of Business Research 58:185- 194.

15. Taghian M, Shaw RN (2008). The marketing audit and organizational performance: an empirical profiling. Journal of Marketing Theory and Practice, 16(4):341.

16. ${ }^{* * *}$ Trade Registry Commerce (2012). Report number 525537. 